\title{
EFL STUDENTS' USE OF GRAMMATICAL INFORMATION IN FIVE LEADING BRITISH LEARNERS' DICTIONARIES
}

\begin{abstract}
Grammar is one of the elements of lexicographic description. In order to find out whether dictionary users use their dictionaries to retrieve grammatical information, we carried out a research-based study investigating their skills. This article presents and discusses the results of a study into the use by EFL students of grammatical information included in five leading British learners' dictionaries. The ability of students to use dictionary entries was tested by means of 33 sentences. Some of the sentences were grammatically correct; others contained a grammatical mistake. The students had to detect mistakes with the help of enclosed dictionary entries. The aim of the study was to find out whether there were any great differences among the dictionaries used and how successful the test subjects were in finding and using grammatical information.
\end{abstract}

\section{Introduction}

Undoubtedly, foreign learners use their bilingual and monolingual dictionaries when they come across an unknown word or phrase, when they do not know or cannot remember an appropriate expression, when they want to check spelling, pronunciation, collocations, idioms or the grammar of a particular word. Cowie (1999: 180) mentions that bilingual dictionaries are used at all levels for decoding, whereas the monolingual ones come into their own as a source of meanings at the more advanced level when the knowledge of L2 is much better. But how good are foreign learners at finding the pieces of information they really need? In order to find this out, many studies have been conducted into the users and uses of learners' dictionaries in the last 25 years, the studies testing different aspects, such as the frequency of use of dictionaries, the types of information the users most often seek, the retrieval of multi-word items, the use of a dictionary for reading, the use of a dictionary for translation purposes, and dictionary look-up processes (Atkins 1998, Battenburg 1991, Béjoint 1981, Cowie 1999, Nuccorini 1992, Tomaszczyk 1979, Tono 2001). As is evident from many studies, foreign learners of English use their dictionaries primarily for meanings, which is followed by other types of information, such as synonyms, idioms, spelling, pronunciation, syntactic patterns or grammar (Béjoint 1981, Tomaszczyk 1979).

Grammar is by no means an unimportant element of a dictionary entry. Learners' dictionaries employ various means for incorporating information on the grammar of the individual words they list. Grammatical information (McCorduck 1993: 13-26) can be 
included in a direct way (e.g. in the form of usage notes, explanatory notes, abbreviations, coded symbols or abbreviated phrases) or in an indirect way (e.g. definitions, examples of use). As regards frequency of use of grammatical information, most studies report that dictionary users consult syntactic information quite commonly (Béjoint 1981, Herbst and Stein 1987), whereas some studies show that users employ this grammatical information infrequently (Battenburg 1991, Nuccorini 1992).

The information on frequency of use of grammatical information is not indicative of the users' reference skills. Is it that those users who infrequently (or never) consult the dictionary as regards grammar are unaware of the fact that grammar is included in monolingual learners' dictionaries? And do those users who ordinarily seek grammatical information know how to use it correctly when encoding?

Much has been written about the role of grammar in the dictionary as well as about the place and nature of grammatical information in learners' dictionaries, but very little has been said about the usefulness or the usability of the various systems that can be found in such dictionaries (Bogaards and van der Kloot 2001: 97). With this in view, we decided to devise a questionnaire aimed at testing the users' capacity to retrieve grammatical information from various parts of a dictionary entry and consequently to be able to use this information appropriately. Our initial hypothesis was that a dictionary should be of great help when users are not quite sure about the grammatical features of the entry word. Consequently, we assumed that there should be a causal relationship between the correct responses and the use of dictionaries. The results of this study are presented and discussed in this article.

\section{METHODOLOGY}

\subsection{Test Subjects}

Research was carried out among 162 students of the University of Ljubljana, Slovenia. One hundred and fifty-seven respondents (i.e. $96.9 \%$ ) speak Slovene as their mother tongue and 5 (i.e. $3.1 \%$ ) speak some other language as their mother tongue. The test subjects were asked to give details about the number of years they had been studying English. Most of the respondents (i.e. 69.1 \%) had been studying English for 10-12 years, $15.4 \%$ had studied it for less than 10 years and $15.4 \%$ for more than 12 years. Our test subjects were considered as belonging to a quite homogenous group: most of them attended schools in Slovenia; they had the same number of English lessons per year and covered the same syllabus. For these reasons we considered it unnecessary for them to undergo a placement test. However, we did enquire about the students' average grades in English in grammar school. The majority of students indicated that their average school grade in English was either A (37\%) or B (34.6\%), 24.1\% had a Grade of C and only $4.3 \%$ a Grade of D.

\subsection{Test Design}

The questionnaire consisted of two parts: a Dictionary User Profile Form and a Dictionary Research Test. The Dictionary User Profile Form was aimed at obtaining information about the dictionary users, i.e. their mother tongue, how long they had been studying English, their grades in grammar school (cf. 2.1 Test Subjects). The 
next few questions concentrated on the frequency of use of monolingual dictionaries, on the frequency of looking up grammatical information, on the types of grammatical information they most often look up and on whether they check grammatical codes or abbreviated phrases they do not understand in the front matter (cf. 3. Users' habits concerning the retrieval of grammatical information).

The Dictionary Research Test concentrated on the respondents' abilities to retrieve grammatical information in five leading British monolingual learners' dictionaries: COBUILD4, OALD6, CALD2, LDOCE4, and MED1. It consisted of 33 sentences, 5 of them with the noun statistic, 7 with the noun experience, 5 with the verb commit, 5 with the verb afford, 6 with the adjective nice, and 5 with the adjective alive. The respondents had to read the sentences and find out whether there were any grammatical mistakes in the use of the above-mentioned words. The grammatical mistakes the students were supposed to find were the following:

- in sentences containing the nouns statistic and experience: plural vs. singular use (depending on the meaning), countable vs. uncountable, prepositions that follow a noun;

- in sentences containing the verbs commit and afford: reflexive use, the verb is followed by the preposition and the gerund (not to-infinitive), the use of appropriate prepositions, spelling changes in inflected forms, the obligatory use of the modal verb ('can' in connection with the verb 'afford'), the verb cannot be used in the passive, transitivity;

- in sentences containing the adjectives nice and alive: predicative vs. attributive use, prepositions that follow a particular adjective, comparison (inflected vs. paraphrastic), grammatical structures that follow the adjective.

The test subjects had to decide which sentences were correct (in this case they had to tick the sentence) and which incorrect (in this case they had to correct the mistake). They were subdivided into five groups depending on the dictionary tested. Accordingly, the Dictionary Research Test was accompanied by a specially designed booklet with dictionary entries for the above-mentioned words taken from one of the learners' dictionaries. Thirty-two students were given the booklet with entries taken from MED1, 32 from OALD6, 31 from LDOCE4, 36 from COBUILD4, and 31 from CALD2. The students were encouraged to use these dictionary entries as much as possible. Each sentence was followed by a question asking the students whether they had consulted the enclosed dictionary entry or not, and if they had, they were asked to answer the next question, i.e. where in the dictionary entry they had found the necessary piece of information. The aim of the last question was to test whether dictionary users are able to identify the appropriate sense of the word in context and consequently, to be able to retrieve grammatical information concerning one particular sense of the entry word.

\subsection{Procedure of data collection}

For the purpose of this study, data were collected by means of a questionnaire accompanied by booklets with relevant dictionary entries. Test subjects were given the questionnaire, and the researchers explained what they had to do. The respondents were supposed to complete the questionnaire in 60 minutes. The respondents' answers were 
appropriately coded and prepared for a statistical analysis using the Microsoft Excel program. Standard statistical methods were used for the data processing, which was carried out by the SPSS for Windows, version 11.

\section{USER HABITS CONCERNING THE RETRIEVAL OF GRAMMATICAL INFORMATION}

Before testing the students' actual skills in retrieving grammatical information from EFL dictionaries, we wanted to obtain some basic information about their everyday use of dictionaries. That is why the Dictionary User Profile Form included some additional questions to provide insight into the students' dictionary habits. First of all, we enquired about the frequency of use of monolingual dictionaries. The results show that $40.1 \%$ of the test subjects only rarely use their monolingual dictionary, $32.7 \%$ evaluated their use of dictionaries as 'frequent'; $21 \%$ are regular dictionary users, and only $5.6 \%$ do not use their monolingual dictionary at all $(0.6 \%$ provided no answer). This question was aimed at getting information about the general use of monolingual dictionaries, whereas the next question concentrated on the frequency of consulting monolingual dictionaries to obtain grammatical information. The results were far from being encouraging, since only $3.1 \%$ of the test subjects regularly use a dictionary to find grammatical information about the entry word. The majority of the respondents (i.e. $53.1 \%$ ) rarely consult a dictionary when faced with grammatical problems; $27.2 \%$ do that frequently, and $16.7 \%$ never consult a dictionary to solve grammatical dilemmas.

Those students who use the monolingual learners' dictionary to find grammatical information were asked to list some types of grammatical information they most frequently check in their dictionary. The answers that the students gave included: countability (40.7\%), prepositions ( $25.2 \%$ ), part of speech (17.8\%), verb forms $(16.3 \%)$, plural forms $(14.8 \%)$, transitivity $(12.6 \%)$, usage $(3.7 \%)$, and other grammatical information (13.3\%), such as articles, verb patterns, the use of the active or passive voice and information about agreement between a noun and a verb. The results show that countability is by far the most common grammatical information that is checked in dictionaries. All other types of information are far less commonly looked up in dictionaries. What is more, as much as $45.6 \%$ of the students listed various types of non-grammatical information, such as collocations, idioms, register and style labels, pronunciation, spelling, and definitions. The question can be asked why such a high percentage of the students listed non-grammatical information. One reason may be that the respondents were not thinking about grammar per se but rather enumerating any piece of information they most often look up in dictionaries. Another possible reason could be that they use a dictionary only to obtain the most basic information (i.e. meaning, spelling, pronunciation) and neglect a very important information category that all EFL dictionaries include, namely grammar. Unfortunately, spoken communication with the students reveals that many of them are not even aware of the fact that a dictionary includes grammar at all. As has been established, the students, when consulting a dictionary to solve grammatical problems, most frequently enumerate countability. This may be explained by the fact that they encounter the codes U (= 
uncountable) and C (= countable) at a very early stage of learning English, since many beginners' textbooks contain exercises in which students have to distinguish between countable and uncountable nouns. The results obtained in this question give cause for concern, since they are indicative of users' unawareness of grammatical information in dictionaries.

The last question in the Dictionary User Profile Form enquired whether the respondents check an unknown code they encounter in a dictionary in the front matter where all the codes are explained. We believe that this is a very important question because the answers show to what extent the dictionary users are willing to give careful study to unknown codes. Worryingly, only $21.6 \%$ of the respondents regularly check an unknown code, $29.6 \%$ often check it; as much as $39.5 \%$ check it only rarely, and $9.3 \%$ never check it. The results are far from being satisfactory, since they may lead us to conclude that even if dictionary users notice the code, they do not bother at all to decipher it let alone to understand it.

\section{RESULTS}

\subsection{Results for the noun statistic}

The most notable differences can be observed in sentence 2 (i.e. Again, it is the doctor's decision that produces the statistic.), where the students using LDOCE4 and CALD2 performed much better than those using the other three dictionaries, since $67.7 \%$ of the students using LDOCE4 and $51.6 \%$ of those using CALD2 corrected the sentence appropriately, as opposed to no more than $25 \%$ of the students using MED1 and COBUILD4 and $21.9 \%$ of those using OALD6. The best results were obtained for sentence 1 (i.e. This view is supported by statistic published in 1985.), followed by sentence 5 (i.e. We have no reliable statistics on the extent of child abuse and neglect.). On the other hand, the students were least successful with sentence 3 (i.e. This terrible crime will soon become nothing more than statistic in police records.) and only slightly more successful with sentence 2 (i.e. Again, it is the doctor's decision that produces the statistic.).

There are, however, differences in the number of students who performed a look-up operation especially with sentence $2(38.9 \%$ of the COBUILD4 users vs. $71.0 \%$ of the LDOCE4 users) and sentence 3 (36.1\% of the COBUILD4 users vs. $80.6 \%$ of the LDOCE4 users). The highest percentage of students who consulted the dictionary can be found in the group of students who used MED1 when correcting sentence $3(84.4 \%)$, whereas the lowest percentage of look-up operations were performed by the OALD6 users $(34.4 \%)$ in sentence 5 .

The number of students who were able to find the correct sense of the entry word used in a particular sentence differs greatly from dictionary to dictionary and from sentence to sentence. The most glaring discrepancy in the success rate for finding the correct sense can be observed with sentence 3 , where $88.9 \%$ of the students who used MED1 provided a correct answer, as opposed to only $16.0 \%$ of those who used LDOCE4. In sentence 4 , the results show a more balanced situation, as the percentage ranges from $66.7 \%$ to $94.4 \%$.

Table 1 shows the results of this task for the noun statistic. 
Table 1: Results for the noun statistic for all five sentences (in \%)

\begin{tabular}{|l|l|c|c|c|c|c|}
\hline s. & students' responses & MED1 & OALD6 & LDOCE4 & COBUILD4 & CALD2 \\
\hline \multirow{2}{*}{1} & correct answer & 87.5 & 71.9 & 71.0 & 83.3 & 74.2 \\
& used dict. entry & 68.8 & 59.4 & 77.4 & 52.8 & 71.0 \\
& correct sense & 77.3 & 78.9 & 70.8 & 94.7 & 50.0 \\
\hline \multirow{2}{*}{2} & correct answer & 25.0 & 21.9 & 67.7 & 25.0 & 51.6 \\
& used dict. entry & 62.5 & 56.3 & 71.0 & 38.9 & 58.1 \\
& correct sense & 50.0 & 22.2 & 72.7 & 0.0 & 27.8 \\
\hline \multirow{3}{*}{3} & correct answer & 34.4 & 25.0 & 29.0 & 22.2 & 19.4 \\
& used dict. entry & 84.4 & 53.1 & 80.6 & 36.1 & 74.2 \\
& correct sense & 88.9 & 76.5 & 16.0 & 0.0 & 52.2 \\
\hline \multirow{4}{*}{4} & correct answer & 43.8 & 50.0 & 41.9 & 66.7 & 51.6 \\
& used dict. entry & 71.9 & 53.1 & 58.1 & 61.1 & 64.5 \\
& correct sense & 69.6 & 88.2 & 94.4 & 72.7 & 66.7 \\
\hline \multirow{2}{*}{5} & correct answer & 71.9 & 75.0 & 48.4 & 69.4 & 67.7 \\
& used dict. entry & 53.1 & 34.4 & 64.5 & 47.2 & 48.4 \\
& correct sense & 41.2 & 63.6 & 60.0 & 88.2 & 40.0 \\
\hline
\end{tabular}

s. $=$ sentence

It is impossible to make an exact comparison between the results showing the percentage of students who corrected the sentence appropriately and those who indicated the correct sense in the dictionary entry. This is because some students made an appropriate correction without consulting the enclosed dictionary entry. These students are not included in the number of students who performed a look-up operation and consequently not in the number of students who found the correct sense of the entry word. The discrepancy between the total number of students who corrected the sentence, the number of students who consulted the dictionary and those who found the correct sense can be quite large. For example, in sentence 3, 32 students used MED1; 11 of them (34.4\%) corrected the sentence appropriately; 27 (84.4\%) consulted the enclosed dictionary entry, and 24 out of 27 students (i.e. $88.9 \%$ ) found the correct sense. A greater difference, however, can be found in sentence 5, where 32 students used OALD6; 24 of them (75.0\%) corrected the sentence appropriately; only $11(34.4 \%)$ consulted the enclosed dictionary entry, and 7 out of 11 students (i.e. $63.6 \%$ ) found the correct sense.

\subsection{Results for the noun experience}

The comparison of the results indicating how many respondents were able to detect a grammatical mistake in the use of the noun experience clearly shows that the students had serious difficulties with sentence 2 (i.e. Older people have had more experience in life.), where not a single student using MED1, OALD6 and LDOCE4 provided a correct answer, but those using COBUILD4 and CALD2 were only slightly more successful (5.6\% and $3.2 \%$ respectively). Sentence 5 (i.e. Many of us have had an experience of living overseas.) and sentence 1 (i.e. I knew that he had no experience driving in the dark.) also proved to be extremely difficult for the majority of respondents, since the 
percentage of correct answers ranged from $6.3 \%$ to $22.6 \%$ in sentence 5 and from $6.3 \%$ to $45.2 \%$ in sentence 1 . In sentence 3 (i.e. Living alone has been a good experience for her.), they performed quite well, especially the students who used CALD2 (96.8\%) and those who used MED1 (84.4\%).

The highest percentage of the students who used the enclosed dictionary entry, can be observed in sentence 7 (74.2\% of the CALD2 users) and the lowest in sentences 2 and $4(25.0 \%$ of the OALD6 users). In sentence 2 , the difference between the highest (71.0\% of the CALD2 users) and the lowest (25.0\% of the OALD6 users) percentage of the students who performed a look-up operation is most notable, and the most balanced situation among dictionaries can be observed in sentences 5 and 6 .

The results showing the number of students who were able to find the right sense of the noun experience in a certain sentence reveal great differences, especially in sentence 1 $(0.0 \%$ of the students who used LDOCE 4 vs. $100.0 \%$ of the students who used CALD 2$)$, sentence $5(6.3 \%$ of the students who used OALD6 vs. $68.2 \%$ of the students who used CALD2), and sentence 7 (23.8\% of the students who used MED1 versus $91.3 \%$ of the students who used CALD2). The results indicating the percentage of students who found the correct sense show a more even distribution among dictionaries in sentences 2 and 3 (from $31.8 \%$ to $58.3 \%$ in sentence 2 and from $64.7 \%$ to $90.0 \%$ in sentence 3 ).

The results that indicate the performance of students when dealing with the noun experience are summarized in Table 2.

Table 2: Results for the noun experience for all seven sentences (in \%)

\begin{tabular}{|l|l|c|c|c|c|c|}
\hline S. & students' response & MED1 & OALD6 & LDOCE4 & COBUILD4 & CALD2 \\
\hline \multirow{3}{*}{1} & correct answer & 6.3 & 15.6 & 16.1 & 11.1 & 45.2 \\
& used dict. entry & 56.3 & 37.5 & 51.6 & 58.3 & 71.0 \\
& correct sense & 16.7 & 25.0 & 0.0 & 19.0 & 100.0 \\
\hline \multirow{3}{*}{2} & correct answer & 0.0 & 0.0 & 0.0 & 5.6 & 3.2 \\
& used dict. entry & 59.4 & 25.0 & 38.7 & 50.0 & 71.0 \\
& correct sense & 57.9 & 50.0 & 58.3 & 33.3 & 31.8 \\
\hline \multirow{3}{*}{3} & correct answer & 84.4 & 78.1 & 71.0 & 77.8 & 96.8 \\
& used dict. entry & 53.1 & 53.1 & 64.5 & 38.9 & 45.2 \\
& correct sense & 82.4 & 64.7 & 90.0 & 71.4 & 73.3 \\
\hline \multirow{3}{*}{4} & correct answer & 65.6 & 71.9 & 67.7 & 77.8 & 83.9 \\
& used dict. entry & 56.3 & 25.0 & 41.9 & 41.7 & 48.4 \\
& correct sense & 66.7 & 37.5 & 69.2 & 66.7 & 86.7 \\
\hline \multirow{3}{*}{5} & correct answer & 9.4 & 6.3 & 19.4 & 16.7 & 22.6 \\
& used dict. entry & 53.1 & 50.0 & 58.1 & 55.6 & 71.0 \\
& correct sense & 16.7 & 6.3 & 27.8 & 15.0 & 68.2 \\
\hline \multirow{3}{*}{6} & correct answer & 59.4 & 50.0 & 71.0 & 61.1 & 61.3 \\
& used dict. entry & 46.9 & 46.9 & 64.5 & 50.0 & 67.7 \\
& correct sense & 80.0 & 87.5 & 75.0 & 77.8 & 66.7 \\
\hline \multirow{2}{*}{7} & correct answer & 59.4 & 31.3 & 38.7 & 58.3 & 87.1 \\
& used dict. entry & 65.6 & 43.8 & 54.8 & 61.1 & 74.2 \\
& correct sense & 23.8 & 50.0 & 58.8 & 40.9 & 91.3 \\
\hline
\end{tabular}




\subsection{Results for the verb commit}

A large difference can be observed between sentence 5 (i.e. I can't come on Sunday: I'm already commited.) and sentence 2 (i.e. The Government is committed to promote the development and use of public transport.), on the one hand, where the students were not at all successful in detecting a grammatical mistake and correcting it, and sentence 1 (i.e. He committed himself to a course of action.), on the other hand, where they performed relatively well. It is surprising that there were so few correct responses for sentence 5 because the mistake the students had to find was a missing -t- in 'commited' - a mistake the students should not have found too difficult. In this sentence the range between the highest and the lowest percentage of students who managed to find the mistake is the greatest (from $9.4 \%$ to $48.4 \%$ ).

As far as the number of look-ups is concerned, the lowest percentage can be found for sentence $5(33.3 \%)$, whereas many more students made use of the enclosed dictionary entry for sentence 2 (the percentage of students who used the dictionary entry ranges from $53.1 \%$ in MED1 to $81.3 \%$ in OALD6) and sentence 1 (where no great difference is observed if we compare the results by dictionaries - from $66.7 \%$ to $75.0 \%$ ).

The sense in which the verb commit is used in a particular sentence was detected by the largest number of respondents in sentence 4 ; they had relatively few problems with sentence 1 , but sentence 5 proved difficult (especially among the students who used MED1 - $16.7 \%$ and LDOCE4 - 21.4\%). Also worth mentioning is the marked difference between the percentage of students who found the correct sense of the verb commit in sentence 2 using MED1, OALD6, LDOCE4, and COBUILD4 (from $64.7 \%$ to $85.7 \%$ ), on the one hand, and the CALD2 users (only $4.2 \%$ ), on the other.

The results indicating how successful the students were in dealing with the verb commit are shown in Table 3.

Table 3: Results for the verb commit for all five sentences (in \%)

\begin{tabular}{|l|l|c|c|c|c|c|}
\hline s. & students' responses & MED1 & OALD6 & LDOCE4 & COBUILD4 & CALD2 \\
\hline \multirow{3}{*}{1} & correct answer & 68.8 & 81.3 & 64.5 & 69.4 & 74.2 \\
& used dict. entry & 75.0 & 68.8 & 74.2 & 66.7 & 67.7 \\
& correct sense & 45.8 & 45.5 & 95.7 & 87.5 & 76.2 \\
\hline \multirow{3}{*}{2} & correct answer & 12.5 & 25.0 & 29.0 & 22.2 & 29.0 \\
& used dict. entry & 53.1 & 81.3 & 67.7 & 75.0 & 77.4 \\
& correct sense & 64.7 & 84.6 & 85.7 & 74.1 & 4.2 \\
\hline \multirow{3}{*}{3} & correct answer & 15.6 & 34.4 & 12.9 & 41.7 & 45.2 \\
& used dict. entry & 59.4 & 68.8 & 58.1 & 66.7 & 61.3 \\
& correct sense & 15.8 & 63.6 & 27.8 & 79.2 & 78.9 \\
\hline \multirow{4}{*}{4} & correct answer & 40.6 & 53.1 & 25.8 & 50.0 & 61.3 \\
& used dict. entry & 59.4 & 68.8 & 80.6 & 83.3 & 38.7 \\
& correct sense & 52.6 & 95.5 & 84.0 & 90.0 & 83.3 \\
\hline \multirow{2}{*}{5} & correct answer & 9.4 & 18.8 & 16.1 & 19.4 & 48.4 \\
& used dict. entry & 37.5 & 40.6 & 45.2 & 33.3 & 45.2 \\
& correct sense & 16.7 & 46.2 & 21.4 & 41.7 & 42.9 \\
\hline
\end{tabular}




\subsection{Results for the verb afford}

The percentage of respondents who ticked the correct sentences and corrected the incorrect ones again differs a great deal. The results are worst for sentence 4 (i.e. It is successful because it produces a high quality product on time at a price that can be afforded by the customer.), especially among the users of CALD2 (3.2 \%), LDOCE4 (16.1\%), and MED1 (18.8\%). It should be stressed that the best results were achieved in sentence 1 (i.e. The tree afforded us welcome shade.) and sentence 5 (i.e. My parents used to say that they would not buy that house, even though they could afford.) by the students who used COBUILD4 (66.7\%), but even here the result is far from being satisfactory.

For sentence 1, the greatest number of students performed a look-up operation (especially the students using COBUILD4, LDOCE4, and CALD2), whereas many fewer did so for sentence 4 (only $25.0 \%$ and $25.8 \%$ among the users of COBUILD4 and LDOCE4 respectively) and sentence 5 (only $22.6 \%$ among the users of LDOCE4). The greatest difference in the number of look-ups among dictionaries can be observed for sentence 4 , where only $25.0 \%$ of the students using COBUILD4 consulted the dictionary, as opposed to $50.0 \%$ of the students who used OALD6.

Regarding the number of respondents who found the correct sense of the verb afford in a particular sentence, it can be observed that the students were relatively, if not very successful, especially with sentence 5 (100.0\% among the OALD6 users, $90.9 \%$ among the COBUILD4 users) and sentence 1 (100.0\% among the OALD6 users, $92.3 \%$ among the LDOCE4 and $90.3 \%$ among the COBUILD4 users, as opposed to relatively few CALD2 users $-52.0 \%$ ). In sentence 3 , where the result was the worst, the number of correct answers ranges between $58.8 \%$ and $81.0 \%$, which is far from indicating a poor performance.

The results concerning the verb afford are presented in Table 4 .

Table 4: Results for the verb afford for all five sentences (in \%)

\begin{tabular}{|l|l|c|c|c|c|c|}
\hline s. & students' responses & MED1 & OALD6 & LDOCE4 & COBUILD4 & CALD2 \\
\hline \multirow{4}{*}{1} & correct answer & 40.6 & 62.5 & 64.5 & 66.7 & 45.2 \\
& used dict. entry & 68.8 & 65.6 & 83.9 & 86.1 & 80.6 \\
& correct sense & 86.4 & 100.0 & 92.3 & 90.3 & 52.0 \\
\hline \multirow{4}{*}{2} & correct answer & 18.8 & 28.1 & 64.5 & 36.1 & 58.1 \\
& used dict. entry & 46.9 & 46.9 & 64.5 & 52.8 & 64.5 \\
& correct sense & 66.7 & 73.3 & 90.0 & 84.2 & 80.0 \\
\hline \multirow{3}{*}{3} & correct answer & 53.1 & 46.9 & 61.3 & 63.9 & 58.1 \\
& used dict. entry & 59.4 & 53.1 & 67.7 & 47.2 & 48.4 \\
& correct sense & 68.4 & 58.8 & 81.0 & 58.8 & 66.7 \\
\hline \multirow{4}{*}{4} & correct answer & 18.8 & 34.4 & 16.1 & 30.6 & 3.2 \\
& used dict. entry & 43.8 & 50.0 & 25.8 & 25.0 & 41.9 \\
& correct sense & 78.6 & 81.3 & 62.5 & 66.7 & 46.2 \\
\hline \multirow{4}{*}{5} & correct answer & 50.0 & 59.4 & 64.5 & 66.7 & 48.4 \\
& used dict. entry & 40.6 & 40.6 & 22.6 & 30.6 & 35.5 \\
& correct sense & 76.9 & 100.0 & 71.4 & 90.9 & 81.8 \\
\hline
\end{tabular}




\subsection{Results for the adjective nice}

As regards the results for the adjective nice, we should mention sentence 1 (i.e. Feel this nice and soft material.) and sentence 4 (i.e. Moza was making nice, asking about dinner.), where the students performed poorly. For sentence 1, there was not a single correct answer among the CALD2 users, but the users of MED1 - 3.1\%, COBUILD4 $8.3 \%$, and OALD6 - $12.5 \%$ also did not prove very successful. In sentence 4 , the best result, i.e. $25.8 \%$, was achieved by the CALD2 users, a result which is far from being satisfactory. On the other hand, in sentences 3,5 , and also 2 , the performance was much better (the result being as much as $80.6 \%$ in sentence 2 among the COBUILD4 users).

The highest number of look-ups was performed by the OALD6 users for sentence 1 (i.e. $56.3 \%$ ), as opposed to the OALD6 users for sentence 4 (only $9.4 \%$ ) and the LDOCE4 users in sentence $5(9.7 \%)$. It should also be pointed out that for sentences $3,4,5$, and 6 the number of students who performed a look-up operation never exceeds $50.0 \%$.

The respondents had the greatest difficulties in finding the right sense of the adjective nice in sentence 4 (especially the OALD6 users, where not a single student provided a correct answer, and the COBUILD4 users with only $14.3 \%$ ). They experienced a relatively high number of problems with sentence 5 (especially the OALD6 users with $28.6 \%$, and LDOCE4 and CALD2 users with $33.3 \%$ ). Sentence 2 seems to have been the least problematic because the number of correct responses ranges between $56.3 \%$ (the CALD2 users) and $92.3 \%$ (the OALD6 users). Also worth mentioning is sentence 1 , where only $17.6 \%$ of the COBUILD4 users managed to find the right sense of the adjective nice, as opposed to much better results obtained by the users of other dictionaries (from $62.5 \%$ to $100.0 \%$ ).

Table 5 shows the results of this task for the adjective nice.

Table 5: Results for the adjective nice for all six sentences (in \%)

\begin{tabular}{|l|l|c|c|c|c|c|}
\hline s. & students' responses & MED1 & OALD6 & LDOCE4 & COBUILD4 & CALD2 \\
\hline \multirow{3}{*}{1} & correct answer & 3.1 & 12.5 & 41.9 & 8.3 & 0.0 \\
& used dict. entry & 50.0 & 56.3 & 51.6 & 47.2 & 35.5 \\
& correct sense & 62.5 & 72.2 & 93.8 & 17.6 & 100.0 \\
\hline \multirow{2}{*}{2} & correct answer & 59.4 & 65.6 & 67.7 & 80.6 & 67.7 \\
& used dict. entry & 53.1 & 40.6 & 48.4 & 52.8 & 51.6 \\
& correct sense & 82.4 & 92.3 & 86.7 & 78.9 & 56.3 \\
\hline \multirow{3}{*}{3} & correct answer & 78.1 & 78.1 & 71.0 & 66.7 & 74.2 \\
& used dict. entry & 50.0 & 50.0 & 29.0 & 27.8 & 22.6 \\
& correct sense & 50.0 & 75.0 & 77.8 & 50.0 & 28.6 \\
\hline \multirow{4}{*}{4} & correct answer & 9.4 & 18.8 & 12.9 & 19.4 & 25.8 \\
& used dict. entry & 37.5 & 9.4 & 32.3 & 19.4 & 35.5 \\
& correct sense & 41.7 & 0.0 & 50.0 & 14.3 & 45.5 \\
\hline \multirow{3}{*}{5} & correct answer & 75.0 & 68.8 & 77.4 & 77.8 & 54.8 \\
& used dict. entry & 34.4 & 21.9 & 9.7 & 25.0 & 29.0 \\
& correct sense & 63.6 & 28.6 & 33.3 & 55.6 & 33.3 \\
\hline \multirow{2}{*}{6} & correct answer & 50.0 & 34.4 & 45.2 & 61.1 & 41.9 \\
& used dict. entry & 43.8 & 28.1 & 38.7 & 47.2 & 45.2 \\
& correct sense & 92.9 & 66.7 & 66.7 & 70.6 & 28.6 \\
\hline
\end{tabular}




\subsection{Results for the adjective alive}

The most difficult sentence as regards finding the grammatical mistakes proved to be sentence 4 (i.e. Both sides were fully alive of the vital importance of the crisis.), especially among the students who used the enclosed dictionary entry from COBULD 4 (5.6\%); neither were the students using the entry from OALD6 successful $(25.0 \%)$. The respondents performed relatively well with sentence 1 (i.e. The children were found alive and well after being missing for several days.), where the number of correct responses ranges from $74.2 \%$ to $84.4 \%$ and sentence 3 (i.e. While you're here don't say it, and we might all stand a chance of getting out of here alive.), where between $67.7 \%$ and $83.9 \%$ of the students established that the sentence was correct.

Sentence 4 is also the only sentence containing the adjective alive where more than half of the respondents on average consulted the enclosed dictionary entry (the range being between $41.7 \%$ and $71.0 \%$ ). A markedly low percentage of look-ups can be observed for sentences 2 and 3 . In sentences 1 and 5, the percentage of those who performed a look-up operation was higher but still far from being satisfactory.

The most difficult sentence concerning the right sense of alive proved to be sentence 5 (only $18.2 \%$ of the CALD2 users found the right sense), which was followed by sentence 4 (where not a single respondent using COBUILD4 found the correct sense, which is, indeed, not included in this particular dictionary). The students had fewer problems with sentences 1 and 2, where all OALD6 users indicated the right sense. With the exception of OALD6, the results range from $66.7 \%$ to $77.8 \%$ for sentence 1 and from $45.5 \%$ to $88.9 \%$ for sentence 2 , where the difference in the number of correct responses is much wider.

The results which indicate the performance of students when dealing with the adjective alive are summarized in Table 6.

Table 6: Results for the adjective alive for all five sentences (in \%)

\begin{tabular}{|l|l|c|c|c|c|c|}
\hline s. & students' responses & MED1 & OALD6 & LDOCE4 & COBULLD4 & CALD2 \\
\hline \multirow{4}{*}{1} & correct answer & 81.3 & 84.4 & 74.2 & 80.6 & 77.4 \\
& used dict. entry & 53.1 & 31.3 & 38.7 & 41.7 & 29.0 \\
& correct sense & 70.6 & 100.0 & 66.7 & 66.7 & 77.8 \\
\hline \multirow{3}{*}{2} & correct answer & 43.8 & 50.0 & 51.6 & 41.7 & 48.4 \\
& used dict. entry & 28.1 & 18.8 & 35.5 & 16.7 & 16.1 \\
& correct sense & 88.9 & 100.0 & 45.5 & 50.0 & 80.0 \\
\hline \multirow{3}{*}{3} & correct answer & 78.1 & 78.1 & 67.7 & 75.0 & 83.9 \\
& used dict. entry & 46.9 & 18.8 & 16.1 & 19.4 & 12.9 \\
& correct sense & 53.3 & 83.3 & 40.0 & 71.4 & 100.0 \\
\hline \multirow{4}{*}{4} & correct answer & 25.0 & 40.6 & 51.6 & 5.6 & 41.9 \\
& used dict. entry & 53.1 & 65.6 & 71.0 & 41.7 & 67.7 \\
& correct sense & 35.3 & 66.7 & 77.3 & 0.0 & 47.6 \\
\hline \multirow{2}{*}{5} & correct answer & 50.0 & 68.8 & 67.7 & 72.2 & 64.5 \\
& used dict. entry & 46.9 & 37.5 & 19.4 & 27.8 & 35.5 \\
& correct sense & 33.3 & 41.7 & 66.7 & 40.0 & 18.2 \\
\hline
\end{tabular}




\section{DISCUSSION}

If we compare the results showing how many students were able to find out whether the sentence was correct or incorrect and to correct the incorrect sentence, we can see that the number of correct answers depends very much on the sentence itself and to a lesser extent on the dictionary the students used. Does this mean that all five dictionaries used in our research are comparable in terms of the success rate for retrieving grammatical information? This question could be answered positively, since the majority of results obtained for one sentence do not show great differences. There are, however, certain exceptions that should be commented on.

In this connection we should mention the noun experience. It is noteworthy that the students who used CALD2 performed better than those using the other four dictionaries when correcting the sentences, as well as when finding the correct sense in the dictionary article. And it also has to be stressed that the greatest number of students made use of the enclosed dictionary article (see Table 2). How can this be explained? If we compare this dictionary entry in all five dictionaries, we can see that CALD2 is the one dictionary where only two meanings are included, i.e. one where experience is uncountable and one where it is countable. In the other four dictionaries the entry consists of three senses (two uncountable and one countable). The very binary characteristic of the entry drives it home. In entries with multiple similar senses, this feature of the noun is not foregrounded as much. Additionally, it should be stressed that the noun experience may pose problems for native speakers of Slovene because in Slovene the noun is countable in all senses.

Surprisingly, the students performed rather poorly with sentence 5 including the verb commit, where they had to insert the missing -t-. This poor performance is hard to explain if we compare the inclusion of this piece of information in all five learners' dictionaries: in OALD6 and CALD2, it is included in the same way, i.e. by listing -tt- immediately after the pronunciation, in LDOCE4 and in COBUILD4 one can find all the verb forms listed after the pronunciation, whereas in MED1 it is not included explicitly, but only in examples of use. It must be stressed that the result for the students who used MED1 was the worst, which is understandable, since they probably did not pay much attention to the spelling of the entry word in the examples of use. The difference between those students who used OALD6 (18.8\%) and CALD2 (48.4\%) is much too great, given that both dictionaries include this piece of information in exactly the same way. This discrepancy is beyond comprehension, and it is even more illogical if we compare the number of students who used the enclosed dictionary entries. This number shows that approximately the same number of respondents performed a look-up operation (40.6 $\%$ in OALD6 and $45.2 \%$ in CALD2). On the other hand, the percentage of correct answers given by the LDOCE4 users (16.1\%) and the COBUILD4 users $(19.4 \%)$ is comparable.

In sentence 1 including the adjective nice, the test subjects had to infer from the enclosed dictionary entries that nice in combination with and followed by an adjective cannot be used before a noun. In OALD6 and in LDOCE4 there is an extra note warning users about the correct use of this adjective in this particular sense. Consequently, we assumed that the results of the test subjects using either of these two dictionaries would be more or less the same, but if we compare the results (cf. Table 5), we can see that they 
failed to meet expectations, as only $12.5 \%$ of the OALD6 users managed to correct the sentence appropriately as opposed to $41.9 \%$ of the LDOCE4 users. Such help notes are intended to highlight a certain feature which could cause problems for learners; they are user-friendly because the correct use is briefly explained and illustrated by means of an example. The students, however, either failed to notice it, or they did not manage to make a connection between the help note and the sentence they were supposed to correct. The results obtained from respondents using the above-mentioned dictionaries differ greatly. Although the system of explaining this specific use of the adjective nice is the same in both dictionaries, LDOCE4 provides a slightly more informative note, since in OALD6 the note follows the correct example.

Although our experimental study was based on the hypothesis that the use of a dictionary entry would result in better performance on correcting the sentences, it can be seen from the results that this is often not the case. This can best be illustrated by the results for the adjective alive in Table 6, especially by sentences 1 and 3 , where the students performed (relatively) well but did not consult the enclosed dictionary entries to a satisfactory degree. On the other hand, it can be noticed that in some sentences the number of correct answers is very low even though the students used the dictionaries (e.g. sentence 5 with the noun experience). The only plausible explanation is that the students are simply not sufficiently trained in dictionary use, and consequently, they often fail to find the right sense of the word together with relevant grammatical information. The number of look-ups also differs from sentence to sentence, a factor that can be attributed to the fact that the students may think they know the answer and find it unnecessary to consult the dictionary.

\section{CONCLUSION}

Although there are more or less incidental differences between the results obtained for the same sentence, the conclusion has to be drawn that in our research none of the five dictionaries tested was much better than the others as regards the inclusion of grammatical information. This conclusion confirms the findings of Bogaards and van der Kloot (2001: 118). It is clear that the test subjects did not make full use of the dictionaries. One of the reasons, which may also be the most important, is lack of instruction and training in dictionary use in the course of learning a foreign language. Students often expect their teacher to provide an answer to their questions and are unwilling to consult a dictionary to find it out themselves. Since they are mostly not trained in how to use their dictionaries, they may often be unaware of the wealth of different pieces of information (including grammatical information) they can find in a monolingual learners' dictionary, or if they find a certain piece of information, the question can still be asked whether they know how to use it correctly in a given context. Nowadays, dictionary training is a must. The compilers of learners' dictionaries have already done a great deal towards the simplification of grammatical information included in dictionaries; nevertheless, dictionary users should obtain certain dictionary reference skills necessary to make full use of their dictionaries. Foreign learners would thus become much more efficient dictionary users and consequently more proficient speakers and writers of a foreign language. 


\section{References}

\section{Dictionaries}

Rundel, M. (ed.) 2002. Macmillan English Dictionary for Advanced Learners. (First edition.) Oxford: Macmillan Publishers. (MED1)

Sinclair, J., Sinclair KNight, L., and ClaR, M. (eds.) 2003. Collins Cobuild Advanced Learner's English Dictionary. (Fourth edition.) Glasgow: HarperCollins Publishers. (COBUILD4)

Summers, D. (ed.) 2003. Longman Dictionary of Contemporary English. (Fourth edition.) Harlow, Essex: Pearson Education Limited. (LDOCE4)

WemeIER, S. (ed.) 2000. Oxford Advanced Learner's Dictionary. (Sixth edition.) Oxford: Oxford University Press. (OALD6)

Woopford, K. and JACKson, G. (eds.) 2003. Cambridge Advanced Learner's Dictionary. (Second edition.) Cambridge: Cambridge University Press. (CALD2)

\section{Other literature}

ATkINS, B. T. S. (ed.) 1998. Using Dictionaries: Studies of Dictionary Use by Language Learners and Translators. (Lexicographica Series Maior 88.) Tübingen: Max Niemeyer Verlag.

BÉJOINT, H. 1981. "The Foreign Student's Use of Monolingual English Dictionaries: A Study of Language Needs ond Reference Skills." Applied Linguistics 2 (3), 207-222.

BatTENBuRg, J. D. 1991. English Monolingual Dictionaries. A User-Oriented Study. (Lexicographica Series Maior 39.) Tübingen: Max Niemeyer Verlag.

BOGAARDS, P. and VAN DER KLOOT, W. 2001. "The Use of Grammatical Information in Learners' Dictionaries." International Journal of Lexicography 14: 97-121.

CowIE, A. 1999. English Dictionaries for Foreign Learners: A History. Oxford: Oxford University Press.

HerbSt, T. and StenN, G. 1987. "Dictionary-Using Skills: A Plea for a New Orientation in Language Teaching" in A. Cowie (ed.), The Dictionary and the Language Learner. Papers from the EURALEX Seminar at the University of Leeds, 1-3 April 1985. (Lexicographica Series Maior 17.) Tübingen: Max Niemeyer Verlag, 115-127.

McCorduck, E. S. 1993. Grammatical Information in ESL Dictionaries. (Lexicographica Series Maior 48.) Tübingen: Max Niemeyer Verlag.

NucCornN, S. 1992. "Monitoring Dictionary Use" in W. H. Tommola, K. Varantola, T. Salmi-Tolonen, and J. Schopp (eds.), Euralex '92 Proceedings I-II (Part I). Studia Translatologica, Ser. A, Vol. 2. Tampere, Finland: University of Tampere, 89-102.

ToMAsZczYK, J. 1979. "Dictionaries: Users and Uses." Glottodidactica 12: 103-119.

Tono, Y. 2001. Research on Dictionary Use in the Context of Foreign Language Learning. (Lexicographica Series Maior 106.) Tübingen: Max Niemeyer Verlag.

\section{Povzetek}

\section{KAKO GOVORCI ANGLEŠČINE KOT TUJEGA JEZIKA UPORABLJAJO SLOVNIČNE INFORMACIJE V PETIH VODILNIH BRITANSKIH SLOVARJH ZA TUJCE}

Slovnica sodi med sestavne dele geselskega članka. Da bi ugotovili, ali uporabniki slovarjev uporabljajo slovarje za iskanje slovničnih informacij, smo izvedli raziskavo, v kateri smo preučevali njihove tovrstne sposobnosti. V članku so predstavljeni in razloženi rezultati raziskave o tem, kako govorci angleščine kot tujega jezika uporabljajo slovnične informacije, vključene v pet vodilnih britanskih slovarjev za tujce. S pomočjo 33 povedi smo testirali, v kolikšni meri so uporabniki sposobni uporabljati geseiske članke. Nekatere povedi so bile slovnično pravilne, druge pa slovnično nepravilne. Študentje so morali s pomočjo priloženih geselskih člankov prepoznati napake. S to raziskavo smo želeli ugotoviti, ali obstajajo kakšne razlike med uporabljenimi slovarji in kako uspešni so testiranci pri iskanju in uporabi slovničnih podatkov. 